\title{
Greater Attendance at a Community Weight Loss Programme over the First 12 Weeks Predicts Weight Loss at 2 Years
}

\author{
Carmen Piernas $^{a} \quad$ Fiona MacLean $^{a} \quad$ Paul Aveyard $^{a} \quad$ Amy L. Ahern ${ }^{b}$ \\ Jenny Woolston $^{b}$ Emma J. Boyland ${ }^{c}$ Jason C.G. Halford ${ }^{c}$ Susan A. Jebb ${ }^{a}$ \\ ${ }^{a}$ Nuffield Department of Primary Care Health Sciences, University of Oxford, Oxford, \\ UK; ${ }^{b}$ MRC Epidemiology Unit, University of Cambridge, Cambridge, UK; ${ }^{c}$ Department of \\ Psychological Sciences, University of Liverpool, Liverpool, UK
}

\section{Keywords}

Attendance $\cdot$ Community programme $\cdot$ Weight loss $\cdot$ Behavioural support

\begin{abstract}
Background: There is considerable heterogeneity in long-term weight loss among people referred to obesity treatment programmes. It is unclear whether attendance at face-to-face sessions in the early weeks of the programme is an independent predictor of long-term success. Objective: To investigate whether frequency of attendance at a community weight loss programme over the first 12 weeks is associated with long-term weight change. Methods: Participants were randomised to receive brief support only (control, $n=211$ ), or a weight loss programme for 12 weeks $(n=530)$ or 52 weeks $(n=528)$. This study included participants with data on session attendance over the first 12 weeks $(n=889)$ compared to the control group. The association between attendance (continuously) and weight loss was explored using a linear model. A multi-level mixed-effects linear model was used to investigate whether attendance (categorised as $0,1,2-5,6-9$, and 10-12 sessions) was associated with weight loss at 3, 12, and 24 months compared to the control. Results: For every session attended in the first 12 weeks, the average weight loss was $-0.259 \mathrm{~kg} / \mathrm{session}$ at 24 months $(p=0.005)$. Analysis by attendance group found only those attending 10-12 sessions had significantly greater weight loss $(-7.5 \mathrm{~kg}[95 \% \mathrm{Cl}-8.1$ to -6.9$]$ at 12 months; -4.7 $\mathrm{kg}$ [95\% Cl -5.3 to -4.1$]$ at 24 months) compared to the control group ( -3.4 [95\% Cl -4.5 to $-2.4]$ at 12 months, -2.5 [95\% Cl -3.5 to -1.5 ] at 24 months). Early attendance was higher for people $\geq 70$ years, but there was no evidence of a difference by gender, ethnicity, education, or income. Conclusions: Greater attendance at a community weight loss programme in the
\end{abstract}

C.P. and F.M. contributed equally to this work. 
Piernas et al.: Early Attendance at a Programme and Weight Loss

first 12 weeks is associated with enhanced weight loss up to 24 months. Regular attendance at a programme could be used as a criterion for continued provision of weight loss services to maximise the cost-effectiveness of interventions.

(C) 2020 The Author(s)

Published by S. Karger AG, Basel

\section{Introduction}

Behavioural weight management programmes are recommended for the treatment of overweight and obesity $[1,2]$. There is good evidence that referral from a primary care practitioner to a community-based weight loss programme produces greater weight loss than self-guided efforts and that this is a cost-effective use of public finance [3-6]. However, there is significant inter-individual variation in outcome. Understanding the factors associated with long-term success may help to inform decisions about continued provision of weight loss support, facilitating more cost-effective treatments.

Many studies have examined participant characteristics associated with weight loss, frequently identifying positive associations with older age, male gender, white ethnicity, higher body mass index (BMI) at baseline, and higher levels of physical activity at baseline, but differences between groups are modest [7-11]. Greater overall attendance has also been reported to be associated with greater weight loss $[8,9,11-14]$. A recent study reported that attendance at one third of weekly meetings over 6 months was associated with $5-10 \%$ weight loss, and attendance at two thirds of weekly meetings was associated with $\geq 10 \%$ weight loss at 6 months. In an intervention trial comprising face-to-face and digital support, attendance at the group was more strongly associated with weight loss than use of the website or mobile app [11].

There is also evidence that greater weight loss early in the programme predicts longterm weight loss [7, 10,15-17], and it is likely that weight loss and attendance are mutually reinforcing. However, it is not clear whether attendance at face-to-face sessions in the early weeks of the programme is an independent predictor of long-term success. If so, providers could use regular attendance as a criterion for continued provision of weight loss services.

The Weight loss Referrals for Adults in Primary care (WRAP) trial showed that extending treatment duration from 12 to 52 weeks led to significantly greater weight loss at 24 months [6]. However, only $42 \%$ of participants randomised to receive treatment for 52 weeks were continuing to attend the programme in the last 12 weeks of their referral [6]. Here we report an exploratory observational analysis of the WRAP trial to examine the association between attendance at a community-based weight loss programme over the first 12 weeks of an intervention study ("early attendance") and weight change at 3,12 , and 24 months. Our hypothesis was that higher attendance at the programme was associated with greater weight loss at 1 year. We also examined whether any effect is independent of weight loss achieved at 3 months. For comparison with previous studies, we also examined whether baseline characteristics predict attendance in the first 12 weeks of the programme.

\section{Subjects and Methods}

\section{Study Design}

The trial design, participants, and interventions have been described previously [18]. In summary, WRAP was a multicentre, non-blinded, three-arm randomised controlled trial to examine weight loss after referral from a general practitioner to a commercial provider (CP; WW, formerly Weight Watchers) [6]. Participants received brief support comprising written 
information to encourage self-help (control), or either 12-week or 52-week referrals to a community-based weight loss programme.

A final population of 1,269 eligible participants provided informed consent and were randomised ( $n=530$ to 12-week referral, $n=528$ to 52-week referral, $n=211$ to control). Participants referred to the CP were asked to attend a local WW meeting once a week for the duration of their treatment ( 12 or 52 weeks). Participants were given either 1 voucher booklet for 12 weekly sessions ( 3 months) or 4 voucher booklets given quarterly (to be used once a week over 1 year). In addition, all CP participants were able to access WW digital tools (weband app-based) for the duration of their treatment.

Participants were booked to attend trial measurement appointments at baseline and 3 , 12, and 24 months. Height was measured at baseline only with a stadiometer to the nearest $0.1 \mathrm{~cm}$; weight was measured to the nearest $0.1 \mathrm{~kg}$ wearing light clothing and without shoes or socks (Tanita, Amsterdam, The Netherlands). Self-reported age, gender, ethnic group, education level, employment status, and household income were also collected at baseline and follow-up study visits.

\section{Attendance at the Programme in the First 12 Weeks}

Attendance in the first 12 weeks of the programme was recorded by the CP because the vouchers handed in were registered electronically. Due to a computer system error, for a short time period vouchers were not recorded. For participants who were scheduled to attend during this period, attendance data from self-reported questionnaires was used and a sensitivity analysis conducted excluding self-reported data. Where objective attendance data was missing we considered this to be missing at random, as the only difference between those who had objective attendance data or not was the referral date.

Attendance at the CP was scheduled to be weekly, and early attendance was recorded as a continuous variable (0-12 sessions). All participants referred to the CP (12 or 52 weeks) with available attendance data were categorised into one of 5 groups according to the number of sessions they attended in the first 12 weeks of their referral: 0 sessions, people who had no exposure whatsoever to the programme; $1,2-5$, and 6-9 sessions, people who attended a variable number of sessions sporadically or continuously; or 10-12 sessions, those who strongly engaged and attended most of the sessions (10-12).

\section{Sociodemographic Characteristics}

Ethnicity was self-reported and grouped into White, other, and not stated. Education level data was grouped into: up to General Certificate of Secondary Education (GCSE, usually around 16 years) or equivalent, A Level (around 18 years) or equivalent, university degree or equivalent, and higher degree or equivalent. Employment status was grouped into: "not employed" for those identifying as unemployed, student, or unable to work, "employed" for those who were self-employed or employed by another, and "retired". Household income data was divided into tertiles of GBP $<20,000,20,000-39,999$, and $\geq 40,000$ per annum.

Baseline observations were used for the following variables: age, employment, ethnicity, household income, and level of education. If baseline data was missing but present at subsequent visits $(3,12$, or 24 -month follow-up), this information was used with priority given to the earliest recorded measure.

\section{Statistical Analysis}

All statistical analyses were conducted using STATA 14. Baseline characteristics were described by profile of attendance data, and differences were tested using ANOVA for age; Kruskal-Wallis for BMI; $\chi^{2}$ test for sex, intervention group, education level, and household income; and Fisher's exact test for ethnic group and employment status. 
Piernas et al.: Early Attendance at a Programme and Weight Loss

To investigate the association between weight loss and early attendance at the $\mathrm{CP}$, we used a multivariable linear model treating attendance as a continuous exposure $(0-12$ sessions). For the main analysis, a multi-level mixed-effects linear regression model with unstructured dependence variance-covariance structure was used treating attendance as a categorical exposure $(0,1,2-5,6-9$, and 10-12 sessions). Each categorical attendance group was compared to the control group of the trial given that these participants did not receive a referral to a CP. To determine whether weight change for each attendance group was significantly different from the control group at each time point $(3,12$, and 24 months), an interaction term (attendance group $\times$ visit) was included in the model. Potential confounders identified by the literature and available in the dataset were baseline age, sex, BMI, ethnicity, education level, employment status, and household income. All were included in the models, in addition to the allocated intervention group (referral for 12 or 52 weeks or control) and attendance data source (CP-reported or self-reported). A separate model was conducted to analyse the association between early attendance and weight loss at 12 and 24 months while controlling for the amount of weight lost at 3 months. In exploratory analyses we ran those models within each of the intervention groups separately (12-week vs. 52-week referral). A sensitivity analysis was conducted to exclude those with only self-reported attendance data.

The association between baseline characteristics and early attendance was analysed using a multivariable linear regression model with attendance treated as a continuous variable (e.g., number of sessions attended over the first 12 weeks).

\section{Results}

The final sample analysed in this study $(n=1,100)$ included participants with objectively recorded attendance data $(n=632)$ or self-reported attendance data $(n=257)$, as well as those in the control group $(n=211)$ who were not referred to CP (online suppl. Appendix 1; see www.karger.com/doi/10.1159/000509131). We excluded 169 participants who had missing information on attendance (objective and/or self-reported). Compared to the final study sample, those with missing attendance data were younger ( $49.9 \pm 13.9$ vs. $54.1 \pm 13.5$ years, $p<0.001$ ); more likely to have been referred for 12 weeks ( 61 vs. $48 \%, p<0.01$ ), and less likely to be retired from work ( 19 vs. $32 \%, p<0.05$ ).

Table 1 shows the baseline characteristics of participants referred to $\mathrm{CP}$ with available attendance data. Of those with early attendance data $(n=889)$, the mean age at baseline was $54.1 \pm 13.5$ years, the median BMI was $33.3 \mathrm{~kg} / \mathrm{m}^{2}$ (IQR 30.6-37.1), 69\% were female, and $92 \%$ reported their ethnicity as White.

Among those referred to a CP the median number of early sessions attended was 11 (IQR 6-12) from a possible 12. Of these, 76 (9\%) participants did not attend any sessions in the first 12 weeks, 36 (4\%) only attended 1 session, 90 (10\%) attended between 2 and 5 sessions, $131(15 \%)$ attended between 6 and 9 sessions, and 556 (63\%) attended 10 or more sessions. This pattern of attendance in the first 12 weeks was not different between the intervention groups (Table 1; CP 12 vs. 52 weeks, $p=0.323$ ), but the mean age was significantly different across the attendance groups $(p<0.001)$. Although all participants had access to web- and app-based tools, participants mostly reported they "never or almost never" used web-based tools at 3 months $(67,75,62,53$, and $49 \%)$ or app-based support $(81,75,68,79$ and $76 \%)$ among participants attending $0,1,2-5,6-9$, or $10-12$ sessions, respectively.

\section{Early Attendance and Weight Change}

In the continuous analysis (Table 2), for every session attended in the first 12 weeks, average weight loss was $-0.297 \mathrm{~kg}$ per session at 3 months $(p<0.001),-0.404 \mathrm{~kg}$ per session

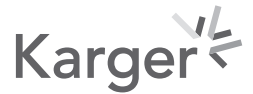




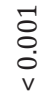

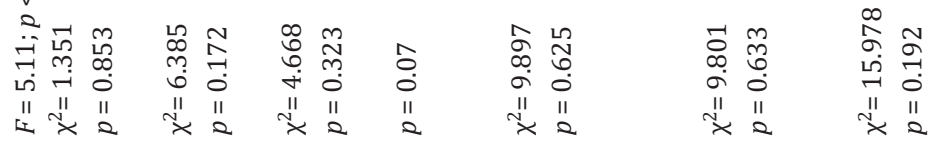

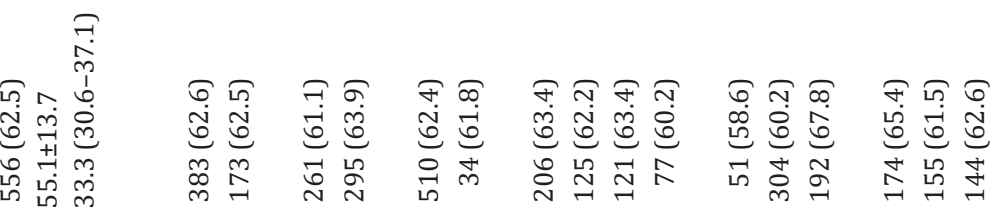
(

$\pi^{2}$

F⿻

อซ ซส

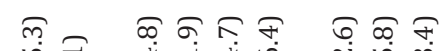

F

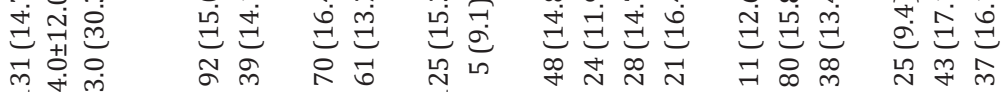
में

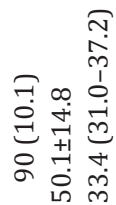

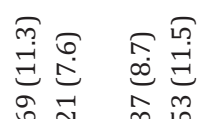

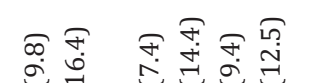

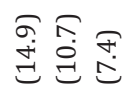

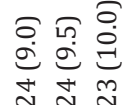

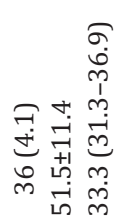

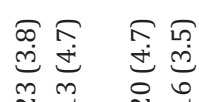

ㄷำ

อㄷำ อำ

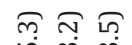

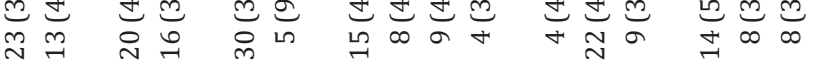

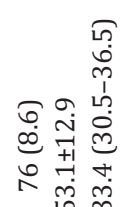

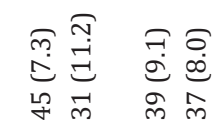

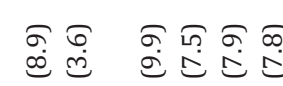

กุ

g.

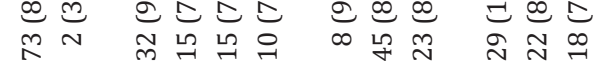

\section{œి $\underset{\infty}{\infty} \underset{\infty}{\infty}$}

ㄱํㅅำ

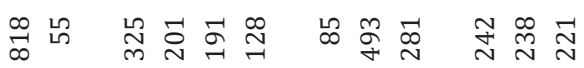

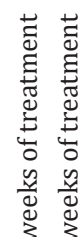

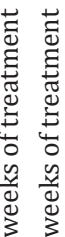

ㄱ.

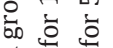

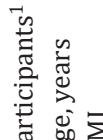

ฮี त्व 瓜地

焉

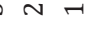


Table 2. Weight change at each time point for every extra session attended during the first 12 weeks among participants of the WRAP trial

\begin{tabular}{llll}
\hline & Weight change, $\mathrm{kg}$ & $95 \% \mathrm{CI}$ & $p$ value \\
\hline Unadjusted model $^{1}$ & & & \\
$\quad 3$ months & -0.306 & -0.369 to -0.242 & $<0.001$ \\
12 months & -0.499 & -0.645 to -0.352 & $<0.001$ \\
24 months & -0.404 & -0.557 to -0.251 & $<0.001$ \\
Multivariable model $^{2}$ & & & \\
3 months & -0.297 & -0.365 to -0.230 & $<0.001$ \\
12 months & -0.404 & -0.558 to -0.251 & $<0.001$ \\
24 months & -0.259 & -0.422 to -0.097 & 0.002 \\
\hline
\end{tabular}

${ }^{1}$ Unadjusted linear regression model. ${ }^{2}$ Adjusted for baseline covariates: age, intervention group, BMI, employment status, ethnic group, household income, sex, and education.

Fig. 1. Weight change (kg) by category of attendance among participants in the WRAP trial.

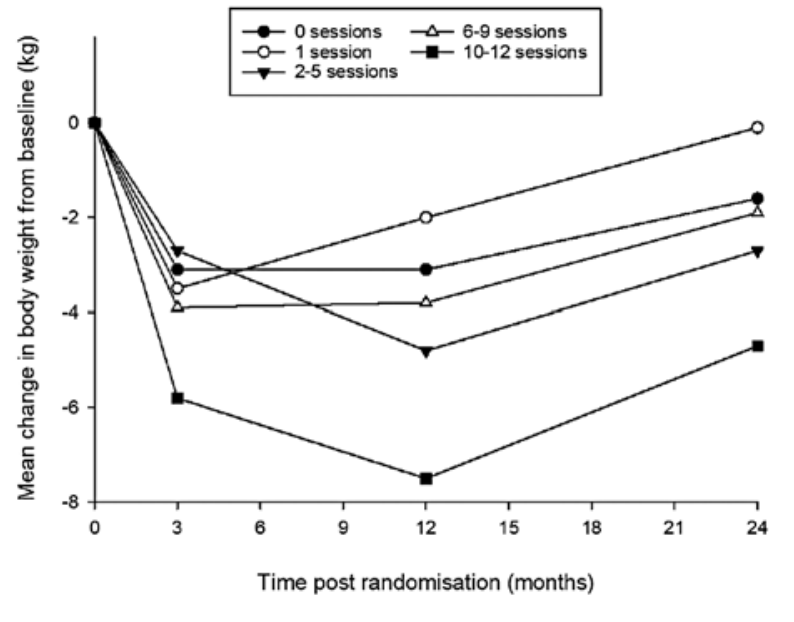

at 12 months $(p<0.001)$, and $-0.259 \mathrm{~kg}$ per session at 24 months $(p=0.005)$ in the fully adjusted model.

Mean weight change in each attendance group at each time point is shown in Figure 1. Only participants who attended 10-12 sessions lost significantly more weight ( -7.5 [95\% CI -8.1 to -6.9 ] at 12 months; -4.7 [95\% CI -5.3 to -4.1 ] at 24 months) compared to the control group ( -3.4 [ $95 \% \mathrm{CI}-4.5$ to -2.4 ] at 12 months, -2.5 [95\% CI -3.5 to -1.5 ] at 24 months) (Table 3). We also investigated the association between each attendance group and weight loss at 12 and 24 months after adjusting for the amount of weight lost at 3 months (Table 3 ). Participants attending 10-12 sessions lost significantly more weight than the control group at 12 months $(-7.5 \mathrm{~kg}[95 \% \mathrm{CI}-8.2$ to -6.8$]$ vs. $-3.8 \mathrm{~kg}$ [95\% CI -5.0 to -2.7$], p<0.001)$ and 24 months ( $-4.7 \mathrm{~kg}[95 \% \mathrm{CI}-5.4$ to -4.0$]$ vs. $-3.1 \mathrm{~kg}[95 \% \mathrm{CI}-4.3$ to -1.9$], p=0.034$ ).

Additional exploratory analyses investigated the associations within each of the active intervention groups separately (12-week and 52-week referral) and found results consistent with those presented in the main analysis described above.

In a sensitivity analysis excluding those with only self-reported attendance data, the conclusions from the main model as well as for the second model adjusted for weight loss at 3 months were unchanged.

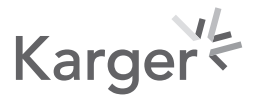




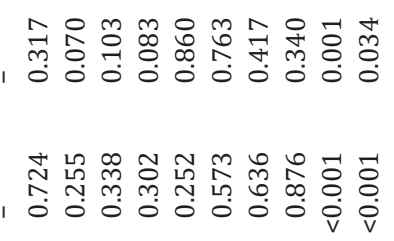

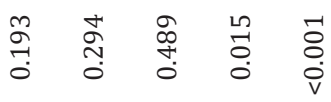

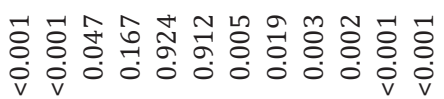

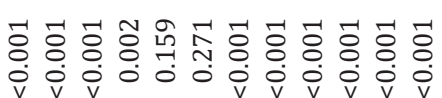

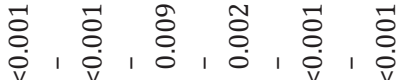

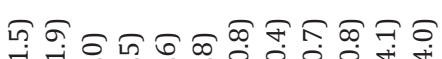

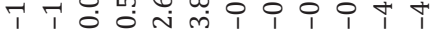

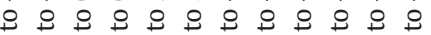
$m \vec{r}$

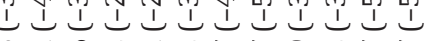
岸

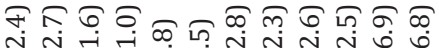

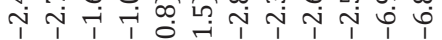

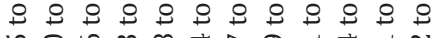

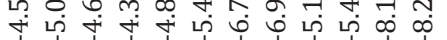

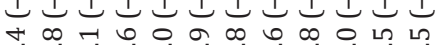
mं山

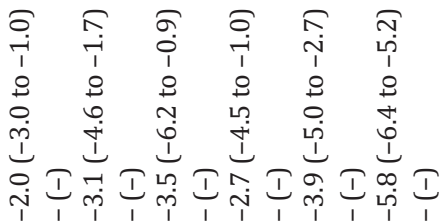

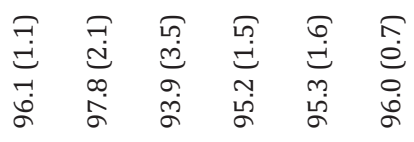

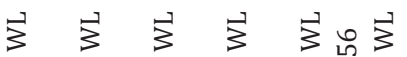

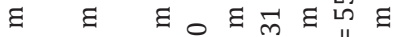
$m m$ m $m \rightarrow n \| m$

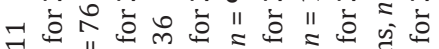

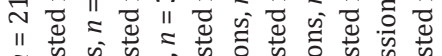

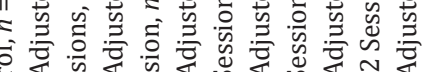

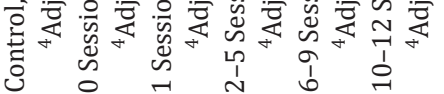

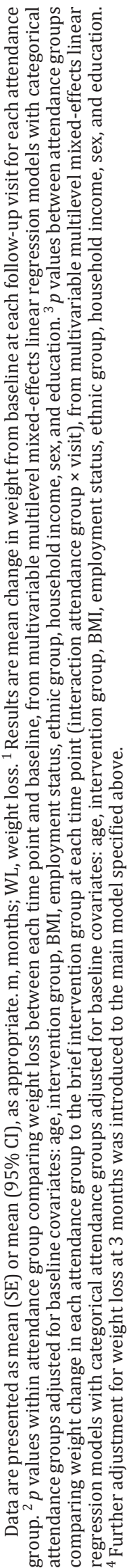


Piernas et al.: Early Attendance at a Programme and Weight Loss

Table 4. Baseline predictors of early attendance at the programme among participants of the WRAP trial

\begin{tabular}{|c|c|c|c|}
\hline & $\beta$ & $95 \%$ CI & $p$ value \\
\hline \multicolumn{4}{|l|}{ Sex } \\
\hline Male & -0.15 & -0.83 to 0.53 & 0.673 \\
\hline \multicolumn{4}{|l|}{ Age group } \\
\hline $30-39$ years & -0.34 & -2.06 to 1.38 & 0.701 \\
\hline $40-49$ years & 0.30 & -1.30 to 1.90 & 0.712 \\
\hline $50-59$ years & 0.08 & -1.53 to 1.68 & 0.925 \\
\hline $60-69$ years & 0.83 & -0.92 to 2.58 & 0.353 \\
\hline $70+$ years & 2.42 & 0.37 to 4.47 & 0.021 \\
\hline \multicolumn{4}{|l|}{ BMI $\left(\mathrm{kg} / \mathrm{m}^{2}\right)$} \\
\hline $30-34.99$ & 0.09 & -0.81 to 1.00 & 0.837 \\
\hline $35-39.99$ & 0.37 & -0.63 to 1.37 & 0.471 \\
\hline$>40$ & 0.58 & -0.64 to 1.79 & 0.351 \\
\hline \multicolumn{4}{|l|}{ Education } \\
\hline A-Level, post-secondary study & 0.52 & -0.35 to 1.38 & 0.240 \\
\hline University degree & 0.53 & -0.35 to 1.40 & 0.239 \\
\hline Higher degree & 0.24 & -0.79 to 1.27 & 0.645 \\
\hline \multicolumn{4}{|l|}{ Household income (GBP per annum) } \\
\hline $20,000-39,999$ & 0.01 & -0.80 to 0.82 & 0.982 \\
\hline $40,000+$ & 0.21 & -0.70 to 1.13 & 0.647 \\
\hline \multicolumn{4}{|l|}{ Ethnic group } \\
\hline Other & -0.44 & -1.70 to 0.81 & 0.491 \\
\hline \multicolumn{4}{|l|}{ Allocated intervention group } \\
\hline Referral for 52 weeks of treatment & 0.21 & -0.42 to 0.84 & 0.510 \\
\hline \multicolumn{4}{|l|}{ Employment } \\
\hline Employed & 0.74 & -0.53 to 2.00 & 0.251 \\
\hline Retired & 0.30 & -1.26 to 1.86 & 0.707 \\
\hline Constant & 7.09 & 5.01 to 9.16 & $<0.001$ \\
\hline
\end{tabular}

Results are $\beta(95 \% \mathrm{CI})$ from multivariable linear regression models, with the following reference groups: female, $<30$ years of age, BMI $<30$, White, education level up to GCSE, household income GBP $<20,000$ per annum, referral for 12 weeks of treatment, and not employed.

\section{Baseline Correlates of Attendance}

In multivariable linear models, sex, BMI, education, income, employment, ethnicity, and intervention group were not significantly associated with attendance (Table 4). Participants aged $\geq 70$ years of age attended an average of 2.38 (95\% CI 0.29-4.48) more sessions than the reference group aged $<30$ years. This difference was still significant at the $5 \%$ level after Bonferroni corrections to account for multiple testing.

\section{Discussion}

Greater attendance at a community weight loss group in the first 12 weeks of the programme is associated with greater weight loss at 24 months. Weight loss among participants attending $\geq 10$ of the first 12 sessions was greater than for all other attendance groups at 12 and 24 months. The association between early attendance and long-term weight loss is independent of the planned duration of the programme. The only significant sociodemographic predictor of greater attendance was age, with the older age group attending significantly more sessions than the younger age group.

The main strength of this study is that it is based on a large randomised controlled trial with 24-month follow-up data. Including body weight for participants in the control group in 
Piernas et al.: Early Attendance at a Programme and Weight Loss

the model allows us to isolate the effect of programme attendance from participation in a research study. This is important because evidence suggests that participation in a trial positively impacts on outcomes regardless of the intervention itself, leading to inflated estimates of the treatment effect in the absence of a control group [19]. Attendance at a programme is often self-reported, whereas here we use objectively collected attendance data for $60 \%$ of participants, which provides confidence that the associations found are not caused by reporting bias. Unfortunately, the study is limited by a computer system error which meant that attendance data was missing for $40 \%$ of participants and we had to rely on self-reported information on attendance. However, in a sensitivity analysis the exclusion of self-reported data did not change the observed associations. Another limitation was the small sample sizes in some of the attendance groups which limited the power of the exploratory and sensitivity analyses, although these were consistent with the main analysis. This analysis was also constrained by the data collected in the main randomised controlled trial, and hence this observational analysis may still be affected by residual confounding related to factors such as prior history of weight loss or motivation to lose weight.

Early attendance at the programme was very high, with over $60 \%$ of participants attending 10 or more sessions in the first 12 weeks (based on objectively recorded attendance data). This is similar to an independent analysis of 29,326 NHS referrals to the same programme which found that $54 \%$ of those referred attended all 12 sessions [20]. Another external audit of a different provider reported that approximately $58 \%$ of those referred attended $\geq 10$ out of 12 sessions [21]. There was no difference in weight loss for groups of people attending for $<10$ weeks compared to the control group. However, the relatively small proportion of people attending $<10$ sessions makes it difficult to establish whether there is a threshold level of attendance or a specific pattern of attendance (e.g., attending once or twice a month but regularly) which is associated with positive outcomes. The proportion of participants self-reporting use of web- or app-based tools was low, particularly among those attending very few face-to-face sessions.

The finding that early weight loss is a strong predictor of long-term weight loss confirms previous findings [16, 17], and the positive association between attendance and weight loss is also consistent with the existing literature across a range of different behavioural weight loss programmes $[9,12,22,23]$. However, additionally we have shown that early attendance predicted weight loss independent of the amount of weight lost over the first 12 weeks and independent of the length of treatment programme that participants were offered.

Most of the sociodemographic characteristics measured in our study were not associated with attendance, except age. Other studies have also identified older age as being associated with higher attendance $[8,15,22]$ and in some cases White ethnicity and education [24]. Other studies have shown that psychosocial factors, such as self-efficacy or being in the "action" stage of change, high perceived risk of cardiovascular disease, or a diagnosis of diabetes, are positively associated with greater overall attendance [25]. But the differences between groups are small.

In routine practice it is not appropriate for practitioners to use sociodemographic factors as predictors of the likelihood of success in order to select people for referral to a weight loss programme $[7,23,26,27]$. Instead, a more pragmatic approach would be to offer short-term interventions routinely to people who are overweight, which we have previously shown to be effective [5], and to base decisions on continued provision based on attendance at the programme. In the WRAP trial we observed that less than half of participants who received free vouchers to attend the programme for 1 year continued to do so over the last 12 weeks of the 1-year treatment [6], and providers could use regular attendance as a criterion for continued provision of services to improve the cost-effectiveness of these interventions. Future research should address how practitioners can support ongoing attendance, perhaps

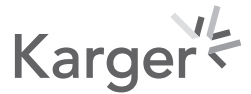


Piernas et al.: Early Attendance at a Programme and Weight Loss

learning from prior research on communication practices to deliver health behaviour change [28].

In conclusion, this study provides evidence that consistent attendance at a communitybased weight loss programme during the first 12 weeks is significantly associated with greater weight loss at 24 months, independent of the magnitude of early weight loss. Regular attendance at a programme could be used as a criterion for continued provision of weight loss services to maximise the cost-effectiveness of interventions.

\section{Acknowledgements}

We thank the practice staff and research assistants who carried out study visits and provided research support over the course of the trial, including Abbey Child, Jessica Strudwick, George Cummins, Hannah Faleti, Carla Greenwood, Chloe Wright, Georgina Hughes, Rachel Dodd, Nicola Williams, Joanne Harrold, Charlie Cruickshank, Monika Epler, Allyson Bradley, and David Timmins; the Volunteer Services and Clinical Studies team at the Medical Research Council (MRC) Human Nutrition Research for supporting data collection at MRC Human Nutrition Research; Jonathan Last, Alison James, and Iain Bayes, who assisted with data entry and data management; and the independent members of the trial steering committee Martin Roland (chair), Nick Finer, Polly Page, Judith Dawson, Norma Scullion, and Graham Rhodes.

\section{Statement of Ethics}

Ethical approval was obtained from the NRES Committee East of England Cambridge East and local approvals from NRES Committee North West Liverpool Central and NRES Committee South Central Oxford. This trial was registered with Current Controlled Trials (No. ISRCTN 82857232). All eligible participants provided informed consent.

\section{Conflict of Interest Statement}

P.A. and S.A.J. are principal investigators of a trial funded by a grant to the University of Oxford from Cambridge Weight Plan. A.L.A. is principal investigator of an NIHR PGfAR-funded trial in which the intervention is delivered by WW at no cost. J.C.G.H. has a trial funded by the American Beverage Association. All other authors declare no competing interests.

\section{Funding Sources}

The WRAP trial is funded by the National Prevention Research Initiative through research grant MR/J000493/1. The funding partners relevant to this award are (in alphabetical order): Alzheimer's Research Trust, Alzheimer's Society, Biotechnology and Biological Sciences Research Council, British Heart Foundation, Cancer Research UK, Chief Scientist Office, Scottish Government Health Directorate, Department of Health, Diabetes UK, Economic and Social Research Council, Health and Social Care Research and Development Division of the Public Health Agency (HSC R\&D Division), UK Medical Research Council (MRC), The Stroke Association, Welcome Trust, Welsh Assembly Government, and World Cancer Research Fund. The cost of the Weight Watchers programme was funded by WW (formerly Weight Watchers

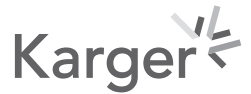


Piernas et al.: Early Attendance at a Programme and Weight Loss

International) as part of an MRC Industrial Collaboration Award. During the conduct of the WRAP trial S.A.J. and A.L.A. were supported by the MRC (grant No. U105960389). S.A.J. and P.A. are currently NIHR Senior Investigators and supported by the Oxford NIHR Biomedical Research Centre and Oxford NIHR Collaboration and Leadership in Applied Health Research and Care (CLAHRC) and Applied Research Collaborations (ARC). C.P.'s time on this project is also supported by the Oxford NIHR CLAHRC and ARC. A.L.A. is supported by the MRC (grant MC_UU_12015/4).

\section{Author Contributions}

C.P., F.M., S.A.J., and P.A.: conceptualization. C.P. and F.M.: data curation and formal analysis. A.L.A., J.W., E.J.B., J.C.G.H., S.A.J., and P.A.: project administration, funding, and resources. All authors: roles/writing - original draft. All authors gave final approval of the submitted and published versions.

\section{References}

1 Centre for Public Health Excellence at NICE (UK); National Collaborating Centre for Primary Care (UK). Obesity: the prevention, identification, assessment and management of overweight and obesity in adults and children. London: National Institute for Health and Clinical Excellence; 2006. Available from: https://www. ncbi.nlm.nih.gov/books/NBK63696/.

2 Stegenga H, Haines A, Jones K, Wilding J; Guideline Development Group. Identification, assessment, and management of overweight and obesity: summary of updated NICE guidance. BMJ. 2014 Nov;349:g6608.

3 Jolly K, Lewis A, Beach J, Denley J, Adab P, Deeks JJ, et al. Comparison of range of commercial or primary care led weight reduction programmes with minimal intervention control for weight loss in obesity: lighten Up randomised controlled trial. BMJ. 2011 Nov;343:d6500.

4 Hartmann-Boyce J, Johns DJ, Jebb SA, Summerbell C, Aveyard P, Behavioural Weight Management Review Group. Behavioural weight management programmes for adults assessed by trials conducted in everyday contexts: systematic review and meta-analysis. Obes Rev. 2014 Nov;15(11):920-32.

5 Aveyard P, Lewis A, Tearne S, Hood K, Christian-Brown A, Adab P, et al. Screening and brief intervention for obesity in primary care: a parallel, two-arm, randomised trial. Lancet. 2016 Nov;388(10059):2492-500.

6 Ahern AL, Wheeler GM, Aveyard P, Boyland EJ, Halford JC, Mander AP, et al. Extended and standard duration weight-loss programme referrals for adults in primary care (WRAP): a randomised controlled trial. Lancet. 2017 Jun;389(10085):2214-25.

7 Greenberg I, Stampfer MJ, Schwarzfuchs D, Shai I; DIRECT Group. Adherence and success in long-term weight loss diets: the dietary intervention randomized controlled trial (DIRECT). J Am Coll Nutr. 2009 Apr;28(2): 159-68.

8 Wadden TA, West DS, Neiberg RH, Wing RR, Ryan DH, Johnson KC, et al.; Look AHEAD Research Group. One-year weight losses in the Look AHEAD study: factors associated with success. Obesity (Silver Spring). 2009 Apr;17(4):713-22.

9 Bartfield JK, Stevens VJ, Jerome GJ, Batch BC, Kennedy BM, Vollmer WM, et al. Behavioral transitions and weight change patterns within the PREMIER trial. Obesity (Silver Spring). 2011 Aug;19(8):1609-15.

10 Handjieva-Darlenska T, Holst C, Grau K, Blaak E, Martinez JA, Oppert JM, et al. Clinical correlates of weight loss and attrition during a 10-week dietary intervention study: results from the NUGENOB project. Obes Facts. 2012;5(6):928-36.

11 Johnston CA, Moreno JP, Hernandez DC, Link BA, Chen TA, Wojtanowski AC, et al. Levels of adherence needed to achieve significant weight loss. Int J Obes. 2019 Jan;43(1):125-31.

12 Acharya SD, Elci OU, Sereika SM, Music E, Styn MA, Turk MW, et al. Adherence to a behavioral weight loss treatment program enhances weight loss and improvements in biomarkers. Patient Prefer Adherence. 2009 Nov; $3: 151-60$.

13 Kumanyika SK, Fassbender JE, Sarwer DB, Phipps E, Allison KC, Localio R, et al. One-year results of the Think Health! study of weight management in primary care practices. Obesity (Silver Spring). 2012 Jun;20(6):124957.

14 Fitzpatrick SL, Bandeen-Roche K, Stevens VJ, Coughlin JW, Rubin RR, Brantley PJ, et al. Examining behavioral processes through which lifestyle interventions promote weight loss: results from PREMIER. Obesity (Silver Spring). 2014 Apr;22(4):1002-7.

15 Fabricatore AN, Wadden TA, Moore RH, Butryn ML, Heymsfield SB, Nguyen AM. Predictors of attrition and weight loss success: results from a randomized controlled trial. Behav Res Ther. 2009 Aug;47(8):685-91. 
16 Unick JL, Hogan PE, Neiberg RH, Cheskin LJ, Dutton GR, Evans-Hudnall G, et al.; Look AHEAD Research Group. Evaluation of early weight loss thresholds for identifying nonresponders to an intensive lifestyle intervention. Obesity (Silver Spring). 2014 Jul;22(7):1608-16.

17 Hadžiabdić MO, Mucalo I, Hrabač P, Matić T, Rahelić D, Božikov V. Factors predictive of drop-out and weight loss success in weight management of obese patients. J Hum Nutr Diet. 2015 Feb;28 Suppl 2:24-32.

18 Ahern AL, Aveyard PN, Halford JC, Mander A, Cresswell L, Cohn SR, et al. Weight loss referrals for adults in primary care (WRAP): protocol for a multi-centre randomised controlled trial comparing the clinical and costeffectiveness of primary care referral to a commercial weight loss provider for 12 weeks, referral for 52 weeks, and a brief self-help intervention [ISRCTN82857232]. BMC Public Health. 2014 Jun;14(1):620.

19 Johns DJ, Hartmann-Boyce J, Jebb SA, Aveyard P; Behavioural Weight Management Review Group. Weight change among people randomized to minimal intervention control groups in weight loss trials. Obesity (Silver Spring). 2016 Apr;24(4):772-80.

20 Ahern AL, Olson AD, Aston LM, Jebb SA. Weight Watchers on prescription: an observational study of weight change among adults referred to Weight Watchers by the NHS. BMC Public Health. 2011 Jun;11(1):434.

21 Stubbs RJ, Pallister C, Whybrow S, Avery A, Lavin J. Weight outcomes audit for 34,271 adults referred to a primary care/commercial weight management partnership scheme. Obes Facts. 2011;4(2):113-20.

22 Wadden TA, Foster GD, Wang J, Pierson RN, Yang MU, Moreland K, et al. Clinical correlates of short- and longterm weight loss. Am J Clin Nutr. 1992 Jul;56(1 Suppl):271S-4S.

23 Moroshko I, Brennan L, O'Brien P. Predictors of dropout in weight loss interventions: a systematic review of the literature. Obes Rev. 2011 Nov;12(11):912-34.

24 Chao DN, Farmer DF, Sevick MA, Espeland MA, Vitolins M, Naughton MJ. The value of session attendance in a weight-loss intervention. Am J Health Behav. 2000 Nov-Dec;24(6):413-21.

25 Leung AW, Chan RS, Sea MM, Woo J. An Overview of Factors Associated with Adherence to Lifestyle Modification Programs for Weight Management in Adults. Int J Environ Res Public Health. 2017 Aug; 14(8):E922.

26 Goode RW, Ye L, Sereika SM, Zheng Y, Mattos M, Acharya SD, et al. Socio-demographic, anthropometric, and psychosocial predictors of attrition across behavioral weight-loss trials. Eat Behav. 2016 Jan;20:27-33.

27 Lemstra M, Bird Y, Nwankwo C, Rogers M, Moraros J. Weight loss intervention adherence and factors promoting adherence: a meta-analysis. Patient Prefer Adherence. 2016 Aug;10:1547-59.

28 Albury C, Hall A, Syed A, Ziebland S, Stokoe E, Roberts N, et al. Communication practices for delivering health behaviour change conversations in primary care: a systematic review and thematic synthesis. BMC Fam Pract. 2019 Aug;20(1):111. 